\title{
Does the Human Development Index relate with acute lymphoblastic leukemia incidence?
}

\author{
Marta Zapata-Tarrés ${ }^{1}$, Liliana Velasco-Hidalgo ${ }^{1}$, Alejandro González-Garay², Rocío Cárdenas-Cardos ${ }^{1}$, and \\ Roberto Rivera-Luna ${ }^{3 *}$ \\ ${ }^{1}$ Department of Oncology; ${ }^{2}$ Department of Methodology; ${ }^{3}$ Division of Hematology/Oncology. Instituto Nacional de Pediatría, Mexico City, Mexico
}

\begin{abstract}
Background: The association between childhood cancer and socioeconomic status has been widely studied. However, none of the results are conclusive. This study aimed to analyze the association between the Human Development Index (HDI) and the acute lymphoblastic leukemia (ALL) incidence in children under the Popular Medical Insurance Care. Methods: We conducted an observational, descriptive, and population-based study covering $55 \%$ of the Mexican population (58 million). Results: The most impoverished states were located in the south east region of Mexico, while the north was more homogeneous, with HDIs varying between 0.73 and 0.79 . Our findings emphasize that the metropolitan area of Mexico City and the State of Nuevo Leon have the highest levels of HDI. Regions were graded from I to IV according to their HDIs in ascending order. The HDls varied from 0.667 to $0.830 / 100,000$ children/year, with a national average of 0.746 . The leukemia incidence for regions I, II, III, and IV was 6.12, 6.53, 4.96, and 9.95. An analysis of ALL incidence in Mexico showed significant differences for region IV in comparison with the other regions based on the HDI values $(p=0.0001)$. Conclusions: Further in-depth studies, including the economic aspects of the different geographic regions and their ethnographic characteristics, would give a more comprehensive panorama.
\end{abstract}

Key words: Human Development Index. Children. Acute lymphoblastic leukemia. Mexico.

\section{¿Existe relación entre el Índice de Desarrollo Humano y la incidencia de leucemia linfoblástica aguda?}

\section{Resumen}

Introducción: Se ha estudiado la relación entre el nivel socioeconómico y el cáncer en niños. Sin embargo, aún no existen resultados concluyentes. El objetivo de este trabajo fue analizar la asociación entre el Índice de Desarrollo Humano (IDH) y la incidencia de leucemia linfoblástica aguda en niños atendidos por el Seguro Popular. Métodos: Se realizó un estudio observacional y descriptivo. La población estudiada representa el $55 \%$ de la población mexicana (58 millones). Resultados: Los Estados más pobres se localizaron en la región sureste de México, mientras que el norte del país fue más homogéneo, con un IDH que varió entre 0.73 y 0.79. Los hallazgos muestran que el área metropolitana de la Ciudad de México y el Estado de Nuevo León tienen un IDH más alto. Las regiones se graduaron del I al IV en orden ascendente de acuerdo con su IDH.

Correspondence:

${ }^{*}$ Roberto Rivera Luna

E-mail: riveraluna@yahoo.com
Available online: 26-01-2021

Date of reception: 19-02-2020

DOI: 10.24875/BMHIM.20000043
Bol Med Hosp Infant Mex. 2021;78(4):301-305 www.bmhim.com

1665-1146/@ 2020 Hospital Infantil de México Federico Gómez. Published by Permanyer. This is an open access article under the CC BY-NC-ND license (http://creativecommons.org/licenses/by-nc-nd/4.0/). 
El IDH varió de 0.667 a 0.830 por 100,000 niños por año, con un promedio nacional de 0.746 . La incidencia de leucemia por 100,000 niños por año en las regiones I, II, III y IV fue de 6.12, 6.53, 4.96 y 9.95, respectivamente. El análisis de variabilidad de la incidencia de leucemia linfoblástica aguda en México muestra diferencias entre la región IV y el resto de las regiones de acuerdo con los valores del IDH $(p=0.0001)$. Conclusiones: Se deben realizar estudios más profundos que consideren no solo los aspectos económicos de las diferentes regiones, sino también sus características etnográficas, 10 cual podría dar un panorama más amplio.

Palabras clave: Índice de Desarrollo Humano. Niños. Leucemia linfoblástica aguda. México.

\section{Introduction}

The association between childhood cancer and socioeconomic status has been widely studied, but none of the results are conclusive. In high-income countries (HIC), the annual incidence of childhood cancer is approximately $14 / 100,000$ children under 15 years of age per year, although estimates may vary within countries ${ }^{1}$. The incidence of leukemia, which is the most common childhood cancer, is 6.4 new cases per 100,000 children per year in low-income countries, $3.65 / 100,000$ children per year in middle-income countries (MIC), and 4.09/100,000 children per year in $\mathrm{HIC}^{2}$. We have outlined the incidence of acute lymphoblastic leukemia (ALL) in Mexico, constantly increasing each year ${ }^{3}$.

Recently, this observation has led to analyze the differences in the incidence of leukemia in other countries. In the United States, for example, a higher incidence has been described in the Hispanic population ${ }^{4}$. Hispanic children are $10-30 \%$ more likely to develop ALL, whereas non-Hispanic white children are nearly two times at risk of developing ALL compared to non-Hispanic black children ${ }^{5}$. In Mexico, isolated studies have reported a higher incidence of ALL in the metropolitan region than the countryside ${ }^{6}$. Several theories have been proposed, ranging from genetic predisposition to infection and exposition to harmful environmental factors, which can be related to the economic background ${ }^{4,7}$.

The association between the economic condition and the incidence of leukemia has been studied in developed countries ${ }^{8}$. In Oslo, people born in low-income families were at risk of developing lymphoid leukemia (odds ratio: 1.72$)^{9}$. In Denmark, there was an increased risk among children born in low-income municipalities (relative risk $[\mathrm{RR}]=2.71 ; 95 \%$ confidence interval $[\mathrm{Cl}]$ $=1.41-5.21 ; p=0.003$ ) and a higher risk among those who were diagnosed with leukemia before 5 years of age $(\mathrm{RR}=3.43 ; 95 \% \mathrm{Cl}=1.52-7.74 ; \mathrm{p}=0.003)^{10}$.

Mexico is a country with substantial economic disparities. However, it is classified as a MIC by the World
Bank ${ }^{11}$. This entity considers the Human Development Index (HDI) a useful tool to classify countries based on health, education, and economic features by small regions ${ }^{12}$. The United Nations developed the HDI to measure social and economic development. It considers life expectancy at birth, income per capita, mean years of schooling for residents of a country, and the expected years of education for children at the average age for starting school.

We aimed to analyze a possible association between the $\mathrm{HDI}$ and childhood incidence of ALL in children register under the Popular Medical Insurance (PMI), a program that finances the treatment of children who have no otherwise universal full healthcare coverage ${ }^{13}$. In Mexico, the Mexican Social Security Institute provides compulsory health insurance to workers in the formal labor market (65 million). State, oil, army, and navy workers have their own social security institutions (14 million). The Ministry of Health provides healthcare to the rest of the population (54 million).

\section{Methods}

We conducted an observational, descriptive, and population-based study. We collected patient data from 2010 to 2015 from the PMI. Population data from children were obtained from the National Institute of Statistics and Geography (INEGI) and the National Population Census of 2010 (this census is conducted every 10 years) ${ }^{14}$.

We included patients under 18 years of age diagnosed with ALL who were registered based on their place of origin and not the place where they were treated. The registered patients belonged to the PMI, and their diagnosis was confirmed by the pediatric oncology team at the hospital.

The incidence of leukemia was evaluated using data for children $<18$ years from the 2010 National Population Census. For incidence calculation, we divided the number of total patients with ALL (PMI) by the number of patients $<18$ years benefiting from PMI. We delimited 
the information by economic regions as our goal was to find an association between the incidence of childhood leukemia and the HDI. We used the economic Sturges' rule to regionalize the country ${ }^{15}$. For the statistical analysis, a Mantel-Haenszel $\chi^{2}$ test was performed according to the type of data.

\section{Economic regionalization}

Thirty-two states of Mexico were included in the analysis. We used the HDI corresponding to each state to obtain the ideal number of classes for each region. We graded each region from I to IV according to the HDI: region I with the lowest $\mathrm{HDI}$ and region IV with the highest HDI. Worldwide, HDI values of $0.667-0.720$, 0.721-0.742, 0.743-0.758, and 0.759-0.83 are considered low, medium, high, and very high, respectively. We calculated the incidence of leukemia for each region using data from each state.

\section{Results}

Mexico is located in North America and covers 964 million km², with 122 million inhabitants (2015). The INEGI estimated a population $<18$ years of $43,523,857$ individuals in 2010. Socio-demographic features showed a very polarized scenario, and wide variations were identified in its $\mathrm{HDI}$ values. The poorest regions were located in the south-east part of the country, while the northern part was more homogeneous, with HDIs varying between 0.73 and 0.79 . The Mexico City metropolitan area in the center and the State of Nuevo Leon in the north of the country showed the highest HDIs. Regions were graded from I to IV in an ascending order based on their HDI values.

By analyzing Mexico's economic and social development aspects, we recorded the $\mathrm{HDI}$, which varied from 0.667 to 0.830 , with an average of 0.746 . The incidence of ALL per 100,000 children per year for regions I, II, III, and IV were $6.12,6.53,4.96$, and 9.95 , respectively (Table 1). The analysis of the ALL incidence in Mexico showed significant differences based on the HDI between region IV and the other regions $(p=0.0001)$. Nine states showed a very high HDI (Mexico City, Nuevo León, Sonora, Baja California Sur, Coahuila, Colima, Querétaro, Baja California, and Aguascalientes); seven showed high HDI (Tamaulipas, Sinaloa, Quintana Roo, Jalisco, Morelos, Campeche, and Estado de México); seven showed a medium HID (Tabasco, Yucatán, Chihuahua, Nayarit, Durango, Tlaxcala, and San Luis Potosí); and nine states showed a low HID
Table 1. Association between HDI and ALL incidence in Mexico

\begin{tabular}{|l|c|c|}
\hline HDI & $\begin{array}{c}\text { ALL incidence } \times \\
\mathbf{1 0 0 , 0 0 0} \text { children }\end{array}$ & $\begin{array}{c}\text { Total cases } \\
\text { of ALL (2015) }\end{array}$ \\
\hline Very high (0.759-0.83) & $9.95^{*}$ & 911 \\
\hline High (0.743-0.758) & 4.96 & 617 \\
\hline Medium (0.721-0.742) & 6.53 & 380 \\
\hline Low (0.667-0.720) & 6.12 & 991 \\
\hline $\begin{array}{l}\chi^{2} \text { test. } \\
\text { *p = 0.0001. } \\
\text { ALL: acute lymphoblastic leukemia; HDI: Human Development Index. }\end{array}$ \\
\hline
\end{tabular}

(Hidalgo, Zacatecas, Guanajuato, Puebla, Veracruz, Michoacán, Oaxaca, Guerrero, and Chiapas). Table 2 summarizes the $\mathrm{HDI}$ and ALL incidences in the four regions and the comparison with other countries.

\section{Discussion}

There has always been an interest in analyzing the economic impact on the incidence, evolution, and mortality of diseases such as cancer ${ }^{16}$. While retinoblastoma and cervical cancer are associated with poverty conditions, Hodgkin's lymphoma is associated with wealth2,17,18.

Poverty or wealth is a much-debated topic of discus$\operatorname{sion}^{19-22}$. The described indices, however, show a partial reality. First, income does not reflect the level of development of a person, community, or region. Therefore, the United Nations has created an index that includes education and health indicators other than financial. This index aims to identify communities for risk studies, but above all, to implement public policies. It also allows the evaluation of the results of these policies from perspectives other than just economic.

The health parameter uses an index that considers access to health protection and household features (number of persons in each bedroom, type of access to water and sanitation, and flooring). The education parameter includes the educational aspiration in children and education in adults $\geq 25$ years. Finally, income is described as the standard of living calculated using the aggregate of the working and non-working family members-income adjusted for international costs (dollars per capita).

The HDI values vary widely in Mexico, ranging from low to very high. Therefore, a relative bias emerges since some communities live in extreme poverty in Mexico, though this is not reflected in these indices. 
Table 2. Comparison between ALL incidence and the HDI in Mexico by regions and other countries

\begin{tabular}{|l|c|c|l|c|c|}
\hline Region & Mexico HDI average & Mexico ALL incidence & Country & Country HDI average & Country ALL incidence \\
\hline I & $0.667-0.720$ & 6.12 & Indonesia & 0.68 & 4.0 \\
\hline II & $0.721-0.742$ & 6.53 & Ecuador & 0.739 & 6.2 \\
\hline III & $0.743-0.758$ & 4.96 & Malaysia & 0.789 & 6.9 \\
\hline IV & $0.759-0.83$ & 9.95 & Latvia & 0.83 & 4.4 \\
\hline Global Mexico & 0.746 & 6.76 & - & - & - \\
\hline
\end{tabular}

ALL: acute lymphoblastic leukemia; HDI: Human Development Index.

Nevertheless, we consider that the $\mathrm{HDI}$ as a parameter for evaluating the general data from across the country is important to compare Mexico with the rest of the world using a standardized tool.

In regions with high $\mathrm{HDI}$, we found ALL incidence to be as high as 9.95 cases per 100,000/year in children $<18$ years, while in the rest of the country (regions I, II, III), where the HDI varied between 0.667 and 0.83 , the mean incidence was 6.76 cases per 100,000 children per year. These findings demonstrate that the ALL incidence in regions with very high $\mathrm{HDI}$ is 1.47 times higher than the rest of the country. However, the relationship between the HDI and leukemia incidence was not uniform: it was higher in states with very high, medium, and low HDI and lower in states with a medium HDI.

In areas with a greater HDI, there is better access to health services, fully equipped medical institutions, and more trained personnel for multidisciplinary care. However, we must note that zone IV states and large urban concentrations, although better medical facilities, also have environmental pollution, overcrowding, and poor drainage.

This study is the first approach toward correlating the $\mathrm{HDI}$ with the geographic distribution of new cases of ALL in children in Mexico. Although it is scientifically complicated to establish a logical or biological relation, the ALL incidence in certain Mexican regions is almost twice the average described for the rest of the world. We can conclude that although Mexico is a country with a wide range of HDls, no state has a very low HDI value. It is also essential to conclude that the HDI variability is due to the varied economic conditions rather than health or education. Similarly, health, economy, and education do not necessarily explain the biological phenomena as a study of mortality would do ${ }^{23-27}$. When considering health, other geographic parameters related to temperature, pollution, climate, and race should also be included ${ }^{28-36}$.
The variability analysis in the ALL incidence in Mexico deserves an in-depth study considering the economic and the ethnographic aspects ${ }^{37}$. The study of markers, potentially modifiable as it is, is essential for presenting the $\mathrm{HDI}$ as a risk factor for this disease.

\section{Ethical disclosures}

Protection of human and animal subjects. The authors declare that no experiments were performed on humans or animals for this study.

Confidentiality of data. The authors declare that they have followed the protocols of their work center on patient data publication.

Right to privacy and informed consent. The authors have obtained the written informed consent of the patients or subjects mentioned in the article. The corresponding author has this document.

\section{Conflicts of interest}

The authors declare no conflicts of interest.

\section{Funding}

None.

\section{References}

1. Steliarova-Foucher E, Fidler MM, Colombet M, Lacour B, Kaatsch P, Piñeros $M$, et al. Changing geographical patterns and trends in cancer incidence in children and adolescents in Europe, 1991-2010 (Automated Childhood Cancer Information System): a population-based study. Lancet Oncol. 2018;19:1159-69.

2. Gupta S, Howard SC, Hunger SP, Antillon FG, Metzger ML, Israels T, et al. Treating childhood cancer in low and middle-income countries. In: Gelband H, Jha P, Sankaranarayanan R, Horton S, editors. Cancer: Disease Control Priorities. Washington, DC: The International Bank for Reconstruction and Development/The World Bank; 2015.

3. Rivera-Luna R, Velasco-Hidalgo L, Zapata-Tarrés M, Cárdenas R, Aguilar MR. Current outlook of childhood cancer epidemiology in a middle-income country under a public health insurance program. Pediatr Hematol Oncol. 2017;34:43-50. 
4. Barrington-Trimis JL, Cockburn M, Metayer C, Gauderman WJ, Wiemels J, McKean-Cowdin R. Trends in childhood incidence over two decades from 1992 to 2013. Int J Cancer. 2017;140:1000-8.

5. Archer NP, Pérez-Andreu V, Stoltze U, Scheurer M, Wilkinson AV Ting NL, et al. Family-based exome-wide association study of childhood acute lymphoblastic leukemia among Hispanics confirms the role of ARID5B in susceptibility. PLoS One. 2017:12:e0180488.

6. Pérez-Saldivar ML, Fajardo-Gutiérrez A, Bernáldez-Ríos R, Martínez-Ávalos A, Medina-Sansón A, Espinosa-Hernández L, et al. Childhood acute leukemias are frequent in Mexico City: descriptive epidemiology. BMC Cancer. 2011;11:355.

7. Mahdavifar N, Towhidi F, Makhsosi BR, Pakzad R, Moini A, Ahmadi A et al. Incidence and mortality of nasopharynx cancer and its relationship with Human Development Index in the world 2012. World J Oncol. 2016;7:109-18.

8. Borugian MJ, Spinelli JJ, Mezei G, Wilkins R, Abanto Z, McBride ML. Childhood leukemia and socioeconomic status in Canada. Epidemiology. 2005;16:526-31.

9. Del Risco Kollerud R, Blaasaas KG, Claussen B. Poverty and the risk of leukemia in the central nervous system in children: a cohort study in a high-income country. Scand J Public Health. 2015;43:73643.

10. Raaschou-Nielsen O, Obel J, Dalton S, Tjonneland A, Hansen J. Socioeconomic status and risk of childhood leukaemia in Denmark. Scand Public Health. 2004:32:279-86.

11. The World Bank. Mexico: World Bank Open Data; 2016. Available from: https://www.data.worldbank.org/country/mexico. Last accessed 13 Aug 2019.

12. Bray F, Jemal A, Grey N, Ferlay J, Forman D. Global cancer transitions according to the Human Development Index (2008-2030): a population-based study. Lancet Oncol. 2012;13:790-801.

13. Rivera-Luna $R$, Zapata-Tarrés $M$, Shalkow-Klincovstein J, Velasco-Hidalgo L, Olaya-Vargas A, Finkelstein-Mizrahi N, et al. The burden of childhood cancer in Mexico: implications for low and middle income countries. Pediatr Blood Cancer. 2017;64:e26366.

14. Instituto Nacional de Estadística y Geografía. Censo de Población y Vivienda 2010. Mexico City: INEGl; 2018. Available from: http://www.beta. inegi.org.mx/proyectos/ccpv/2010. Last accessed 13 Aug 2019.

15. Scott DW. Sturges' rule. WIREs Comput Stat. 2009;1:303-6.

16. Pan IJ, Daniels JL, Zhu K. Poverty and childhood cancer incidence in the United States. Cancer Causes Control. 2010;21:1139-45.

17. Youlden DR, Baade PD, Valery PC, Hassall TE, Ward LJ, Green AC et al. Area-based differentials in childhood cancer incidence in Australia, 1996-2006. Pediatric Blood Cancer. 2012;58:390-4.

18. Poole C, Greenland S, Luetters C, Kelsey JL, Mezei G. Socioeconomic status and childhood leukaemia: a review. Int J Epidemiol. 2006;35:37084.

19. Adam M, Rebholz CE, Egger M, Zwahlen M, Kuehni CE. Childhood leukaemia and socioeconomic status: what is the evidence? Rad Prot Dosimetry. 2008;132:246-54.
20. Hashemizadeh $\mathrm{H}$, Boroumand $\mathrm{H}$, Noori $\mathrm{R}$, Darabian $\mathrm{M}$. Socioeconomic status and other characteristics in childhood leukemia. Iran J Ped Hematol Oncol. 2013;3:182-6.

21. Adam M, Kuehni CE, Spoerri A, Schmidlin K, Gumy-Pause F, Brazzola P, et al. Socioeconomic status and childhood leukemia incidence in Switzerland. Front Oncol. 2015;5:139

22. Kroll ME, Stiller CA, Murphy MF, Carpenter LM. Childhood leukaemia and socioeconomic status in England and Wales 1976-2005: evidence of higher incidence in relatively affluent communities persists over time. Br J Cancer. 2011;105:1783-7.

23. Lacour B, Guyot-Goubin A, Guissou S, Bellec S, Desandes E, Clavel J. Incidence of childhood cancer in France: national cancer registries, 20002004. Eur J Cancer Prev. 2010;19:173-81.

24. Metzger ML, Howard SC, Fu LC, Peña A, Stefan R, Hancock ML, et al. Outcome of childhood acute lymphoblastic leukemia in resource-poor countries. Lancet. 2003;30;362:706-8.

25. Ross JA, Davies SM, Potter JD, Robison LL. Epidemiology of childhood leukemia with a focus on infants. Epidemiol Rev. 1994:16:243-72.

26. Rizo-Ríos P, Sánchez-Cervantes F, González-Rivera A, Betancourt-Cravioto M, Meneses-García A, Mohar A, et al. Mortalidad por leucemias en menores de 20 años. México1998-2002. Bol Med Hosp Infant Mex. 2005;62:9-18.

27. Abdullaev FI, Rivera-Luna R, Roitenburd-Belacortu V, Espinoza J. Pattern of childhood cancer mortality in Mexico. Arch Med Res. 2000;31:526-31.

28. McKinney PA, Fear NT, Stockton D. Parental occupation at periconception: findings from the United Kingdom childhood cancer study. Occup Environ Med. 2003;60:901-9.

29. Sala A, Pencharz P, Barr RD. Children, cancer and nutrition. A dynamic triangle in review. Cancer. 2004;100:677-87.

30. Vijh AK. Inverse trend between estimated worldwide frequency of major cancers and inferred infectious burdens of populations: possible role of adaptive immune system. Med Hypotheses. 2004;62:880-8.

31. Valcke M, Chaverri F, Monge P, Bravo V, Mergler D, Partanen T, et al. Pesticide prioritization for a case-control study on childhood leukemia in Costa Rica: a simple stepwise approach. Environ Res. 2005:97:335-47.

32. Jourdan Da-Silva N, Perel Y, Méchinaud F, Plouvier E, Gandemer V, Lutz $\mathrm{P}$, et al. Infectious disease in the first year of life, perinatal characteristics and childhood acute leukemia. Br J Cancer. 2004;90:139-45.

33. Chang JS. Parental smoking and childhood leukemia. Methods Mol Biol. 2009;472:103-37.

34. Perera F. Molecular epidemiology, prenatal exposure and prevention of cancer. Environ Health. 2011:10:S5

35. Greaves M. Infection, immune responses and the etiology of childhood leukaemia. Nat Rev Cancer. 2006;6:193-203.

36. Petridou ET, Sergentanis TN, Panagopoulou P, Moschovi M, Polychronopoulou S, Baka $\mathrm{M}$, et al. In vitro fertilization and risk of childhood leukemia in Greece and Sweden. Pediatr Blood Cancer. 2012;58:930-6.

37. Wang L, Gomez SL, Yasui Y. Racial and ethnics differences in socioeconomic position and risk of childhood acute lymphoblastic leukemia. Am J Epidemiol. 2017;185:1263-71. 